\title{
Iron filings in tea and its impact on the quality attributes of made tea and tea liquor
}

\author{
U.I. Baby \\ Former Plant Pathologist, UPASI Tea Research Foundation, Tea Research Institute, Valparai-642 127, \\ Tamil Nadu, India \\ (Manuscript Received: 22-05-2020, Revised: 01-10-2020, Accepted: 28-10-2020)
}

\begin{abstract}
Presence of iron filings in made tea (MT) is a serious issue in the tea industry with the implementation of FSSAI regulations. In this scenario, the estimation of iron filings in tea is a critical operation. Unfortunately, the widely accepted method of analysis as per IS 3633 is having a lot of limitations to obtain a reproducible result. Attempts were made to quantify the possible factors affecting the accuracy of the result. Critical attempts were also made to investigate the impact of iron filings on the quality attributes of made tea as well as the tea liquor. Other aspects like adulteration of tea with iron filings and its possible health hazards are also discussed.
\end{abstract}

Keywords: Adulteration, health hazard, iron filings, iron content, made tea, organoleptic evaluation, tea quality attributes

\section{Introduction}

Iron filing is an extraneous matter entering into made tea (MT) during the process of manufacturing. This contamination occurs mainly through the wear and tear of machinery, though many other sanitary measures are also contributing to this malady (Anonymous, 1997; Baby and Murugesan, 2009). This is a serious issue in CTC (Crush Tear Curl) tea compared to orthodox tea as the grinding action of the machinery is more in CTC manufacturing. Unlike other metals, iron is present in two forms in tea; primarily as inherent iron (non-magnetic) and as iron filings (magnetic), the former is plant nutrient (micronutrient) in nature, while the latter is extraneous matter. As per Indian standards (Bureau of Indian Standards-BIS), the permissible level of iron filings in tea is $250 \mathrm{mg} \mathrm{kg}^{-1}$ (BIS, 2003). Food Safety Standards Authority of India (FSSAI) has fixed its level as $150 \mathrm{mg} \mathrm{kg}^{-1}$ (FSSAI, 2015), though revised later to $250 \mathrm{mg} \mathrm{kg}^{-1}$ (FSSAI, 2016). Many countries do not have limits for iron filings in tea (GSO, 1998), while many others have specifications on its level. Accordingly, for some of the developed countries, it is as low as $120 \mathrm{mg} \mathrm{kg}^{-1}$, and for some underdeveloped countries, it is as high as $500 \mathrm{mg} \mathrm{kg}^{-1}$ (Egyptian Standards, 2005). Certain countries have specification for iron as 'total iron' which represent inherent iron as well as iron filings. Accordingly, it is $150 \mathrm{mg} \mathrm{kg}^{-1}$ for Iran, $300 \mathrm{mg} \mathrm{kg}^{-1}$ for Iraq and 500 $\mathrm{mg} \mathrm{kg}^{-1}$ for Sri Lanka (ISIRI, 2012; Sri Lanka Tea Board, 2008).

Iron filings in food products can cause health hazards in human beings. Ingestion of greater than 50 to $100 \mathrm{mg}$ of iron per day may result in iron deposition in body tissues leading to serious health issues. Though there is no scientific evidence that the iron filings in tea pose health hazards, its continuous presence has raised serious safety concerns. Further, with the implementation of stringent regulation of FSSAI act, it has become a serious issue in the tea industry.

Estimation of iron filings in tea is a critical operation because an incorrect result can lead to the rejection of the whole lot in a consignment. Tea Board India has suggested various gravimetric and colorimetric methods for the estimation of iron

*Corresponding Author:dr.babyui@gmail.com 
filings (Anonymous, 1997). Thanaraj and Ramaswamy (1977) compared four different methods comprising colorimetric and gravimetric methods to find out a relatively simple and more reproducible method. They concluded that colorimetric method by ashing and acid digestion of the sample is ideal. But this process is expensive, laborious and time-consuming and hence difficult in situations where more samples have to be handled. Bureau of Indian Standards suggested gravimetric method through magnetic separation (IS 3633 ) for the estimation of iron filings in tea (BIS, 2003), which is widely accepted due to its easiness in operation. Unfortunately, this method has many limitations which lead to inconsistency and/or erratic results. FSSAI suggested DGHS manual (Directorate General of Health Services) for the estimation of iron filings (DGHS, 2005). The analysis methodology of both the standard is essentially the same except the type of sample to be subjected for analysis; the former suggests the analysis on the powdered sample (sample prepared as per IS:13852 (BIS, 1994), while the latter on the unpowdered sample (sample in its own form). However, both the methods are silent on the crucial step of 'post magnetic separation grinding' of the separated 'iron filings' to remove the tea leaf particles (organic part) which entrap the actual iron filings (Fig. 1 E). Since the so-called 'iron filings' have organic part, the values of iron filings thus calculated will be a magnified figure than the actual. Baby (2016) highlighted the factors which can affect the accuracy of the result.

There is a notion in that higher levels of iron filings decreases the density of MT and also improve the colour and liquor quality and hence widely being used as an adulterant. It is also suspected that the presence of iron filings can cause health issues in humans. Further, the impact of iron filings on the quality attributes of MT and tea liquor is also not known. Despite its importance, so far, no work has been done in this line. The present study was taken up in this context and attempts were made to assess the factors influencing the accuracy of the result on the estimation of iron filings and its influence on the quality attributes of MT and tea liquor. Attempts were also made to check the authenticity on the usage of iron filings as an adulterant and also to verify the possible health hazard due to the presence of iron filings in MT.

\section{Materials and methods}

\section{Estimation of iron filings}

The level of iron filings in the tea samples was estimated following three different methods:

(1) By DGHS Method (DGHS, 2005): wherein the magnetic separation was done on the sample as received, i.e., without sample preparation as per IS 13852. The separated particles were weighed and represented as the level of iron filings.

(2) By IS 3633 (BIS, 2003): This method differs from the previous one in that the analysis was done on the samples prepared as per IS 13852, i.e., with pre magnetic separation grinding.

(3) By modified IS 3633 (UPASI method; Baby and Murugesan, 2009): This method differs from method 2 in that the separated iron filings were crushed and ground further to remove the organic particles from the iron filings. i.e., both pre and post magnetic separation grinding were adopted

\section{Sample preparation}

Unless otherwise specified, tea samples for analysis were prepared as per IS 13852 (BIS, 1994). Samples were pooled, mixed thoroughly and brought down to the required quantity by repeated quartering. Approximately $30 \mathrm{~g}$ of sample was homogenized in a blender for 25 seconds with a break for a minute after 12 seconds. This break was given to mix the content in the blender for proper and uniform grinding. The ground powder was sieved through $500 \mu$ mesh test sieve (ASTM 35) and used for all analyses.

\section{Procedure for estimating iron filings}

From the ground and sieved tea powder (but for Method 1), $25 \mathrm{~g}$ was accurately weighed and spread uniformly on a thick white sheet of paper. A rare -earth magnet wrapped with a butter paper was run over the sample. The iron filings stuck on the magnet were transferred into a watch glass. The process is repeated until no iron filings stick on the magnet. The collected 'iron filings' were ground 
again (only for Method 3) in a porcelain mortar with a pestle and spread evenly on the white sheet, and the magnet wrapped with butter paper was run over it. The process of refinement is repeated to get the iron particles completely free from the organic particles. The iron filings thus obtained were transferred into a pre-weighed watch glass and weighed to the nearest $0.1 \mathrm{mg}$, and the level of iron filings was calculated as per the formula:

Iron filings $\left(\mathrm{mg} \mathrm{kg}^{-1}\right)=[$ (weight of iron filings + dish) - (weight of empty dish) ] x 10\% weight of tea sample

\section{Commercial testing of iron filings}

Approximately $100 \mathrm{~g}$ of tea samples of different grades were sent to commercial testing laboratories. The laboratories were advised to analyse the samples, without any deviation from the method that they follow.

\section{Level of iron filings in different dust grades of CTC tea}

Dust grade (Red Dust - RD, Super Red DustSRD and Super Fine Dust - SFD) samples collected from bulk packs of 20 tea estates were checked for iron filings. Five samples of each grade, belonging to different batches were subjected to the analysis

\section{Gauss power of the magnet}

Iron filings were separated from the ground sample with magnets having different gauss power viz., 2000, 5000, 12000. Unless otherwise specified, magnet having strength of 5000 Gauss power was used for all routine analysis.

\section{Shape and size of the magnet}

This experiment was conducted with magnets of different shape (bar, square, cylindrical, and horseshoe type) and size viz., 3"x1", 6"x3.25"(bar magnet) independently with the help of commercial laboratories with their own magnets.

\section{Least count (readability) of the balance}

The iron particles separated from the samples were weighed in electronic balances of different least counts (LC) viz., $0.1 \mathrm{mg}$ and $1.0 \mathrm{mg}$.

\section{Iron-fortified experiments}

Tea samples were fortified with iron filings to various levels to study the impact of the level of iron filings on the quality of made tea and tea liquor (cup quality). The iron filings used for fortification was collected from the magnet fixed in the manufacturing lane of the factory, which contains both iron filings and iron embedded inside the tea granules. Levels of iron filings in the fortified samples were estimated gravimetrically (by Method 3).

The iron-fortified samples were checked for their density and also subjected to the analysis of PFA parameters viz., water extract (BIS 13862: 1999) and water-soluble ash (IS 13855: 1993). These samples were also analysed for total iron in MT as well as in tea liquor, in an ICPOES. The tea liquor quality parameters like Theaflavin (TF), Thearubigin (TR), high polymerized substance (HPS) and total liquor colour (TLC) were analysed following Takeo and Oosawa (1976) and colour value of the liquor by colorimetric method. Estimation of total iron and liquor quality parameters were carried out with the help of commercial laboratories. Besides, these samples were subjected to organoleptic evaluation through professional tea tasters. In one of the tea tasting evaluations, samples were amended with rusted iron powder as well.

\section{Preparations of tea brew for biochemical analysis}

Tea liquor was prepared in hot water as two per cent concentration. Two grams of tea powder was taken in a $250 \mathrm{~mL}$ conical flask, and $100 \mathrm{~mL}$ of freshly boiled distilled water was poured into it and kept on a boiling water bath for $10 \mathrm{~min}$. To ensure maximum extraction, a gentle shake of the flask was given after $5 \mathrm{~min}$. The infusion was filtered into a $150 \mathrm{~mL}$ flask through Whatmann No.1 filter paper. The filtrate thus obtained, termed as tea liquor (brew/infusion) was used for various biochemical estimations.

\section{Preparation of tea liquor for organoleptic evaluation}

For the organoleptic evaluation (sensory evaluation/tea tasting), $3 \mathrm{~g}$ of tea was weighed and taken in a porcelain brewing cup and was filled to the brim with freshly boiled water. The standard cup is of $150 \mathrm{~mL}$ in volume, and so the proportion of tea to water works to two per cent concentration, which is the standard. The brewing cup was closed 
with its porcelain lid and allowed to brew for six minutes. The infusion was then filtered through a strainer in to a porcelain bowl. The infused leaf was transferred into the lid of the brewing cup, pressed firmly with a stainless steel 'presser' and kept over the cup in an inverted position to facilitate the taster to assess its properties. In sensory evaluation, the tasters look for the attributes of the liquor like colour, strength, brightness, briskness, taste and flavour/ aroma. Mostly tea is tasted without milk and sugar. In some cases, milk is also added (1-1 $1 / 2$ spoon) to the liquor while tasting.

\section{Results and discussion}

\section{Gauss power of the magnet}

The iron particles that get separated from the sample increased with the increasing power of the magnet. The value obtained with the magnet of 5000 $\mathrm{G}$ was about 80 per cent more than that obtained with $2000 \mathrm{G}$ magnet. Likewise, with $12000 \mathrm{G}$, it was about 40 per cent more than that obtained with the $5000 \mathrm{G}$ magnet (Table 1).

From the observed trend, it can be inferred that higher-powered magnet was able to yield higher recovery of iron filings from the sample. As the force on a finer iron filing is lower, we need a stronger magnet to provide sufficient force to lift the particle against gravity. A stronger magnet will capture even smaller sized iron filings, thereby increasing the recovery. If a small iron filing is entrapped in a larger tea leaf particle, only a strong magnet will be able to lift the entire particle, which increases the recovery percentage. The result thus revealed the importance of gauss power of the magnet to be used for the analysis. Tea Board India in its recommendation (Anonymous, 1997) suggested using a 'powerful' magnet of 3" long, 1" wide and 0.5 " thick or of any convenient size that can be held easily for operation, neglecting the importance of gauss power of the magnet.

\section{Shape of the magnet}

Recovery of iron filings was highest with the cylindrical magnet and lowest with horseshoe magnet (Table 2). Higher recovery with cylindrical magnet is not because of the shape but due to its higher gauss power $(12000 \mathrm{G})$, despite its heavyweight which can adversely affect the operation. On the other hand, the lowest recovery with horseshoe magnet is obviously due to its shape, because the magnetic area is restricted only to its two tips resulting in low contact area which in turn adversely affect the recovery. Fairly good recovery was obtained with bar magnet of $2000 \mathrm{G}$. However, the recovery was significantly higher with the magnet of $3 " x 1 "$ size compared to 6"x3.25", despite the same gauss power. This may be attributed to the operational difficulty with the magnet of the size

Table 2. Recovery of iron filings from tea sample with magnets of different shape

\begin{tabular}{lcc}
\hline $\begin{array}{l}\text { Shape of magnet/ } \\
\text { Gauss power\# }\end{array}$ & $\begin{array}{c}\text { Iron filings } \\
\left(\mathbf{m g ~ k g}^{-1}\right)\end{array}$ & SD \\
\hline Bar magnet (3" x 1")* & 40 & \pm 4.58 \\
Bar magnet (6" x 3.25")* & 28 & \pm 7.21 \\
Square (5 cm $)^{* *}$ & 92 & \pm 11.14 \\
Cylindrical*** & 112 & \pm 12.49 \\
Horseshoe\$ & 8 & \pm 4.00 \\
\hline \#Gauss power;*2000G, **5000G, ***12000G, \$Not known
\end{tabular}

Table 1. Recovery of iron filings from tea samples with magnets of different Gauss power

\begin{tabular}{lccc}
\hline Sample code & \multicolumn{2}{c}{ Gauss power of magnet/ Level of iron filings $\left(\mathbf{m g ~ k}^{-1}\right)$} \\
\cline { 2 - 4 } & $\mathbf{2 0 0 0}$ & $\mathbf{5 0 0 0}$ & $\mathbf{1 2 0 0 0}$ \\
\hline Sample 1 & $44(\mathrm{SD} \pm 4.00)$ & $76(\mathrm{SD} \pm 5.29)$ & $128(\mathrm{SD} \pm 4.00)$ \\
Sample 2 & $40(\mathrm{SD} \pm 3.46)$ & $72(\mathrm{SD} \pm 3.46)$ & $116(\mathrm{SD} \pm 5.29)$ \\
Sample 3 & $76(\mathrm{SD} \pm 6.00)$ & $136(\mathrm{SD} \pm 4.00)$ & $192(\mathrm{SD} \pm 5.29)$ \\
Sample 4 & $68(\mathrm{SD} \pm 2.00)$ & $128(\mathrm{SD} \pm 4.00)$ & $236(\mathrm{SD} \pm 5.29)$ \\
Sample 5 & $120(\mathrm{SD} \pm 10.00)$ & $220(\mathrm{SD} \pm 5.57)$ & $286(\mathrm{SD} \pm 7.21)$ \\
Sample 6 & $156(\mathrm{SD} \pm 7.21)$ & $244(\mathrm{SD} \pm 5.29)$ & $310(\mathrm{SD} \pm 7.21)$ \\
Sample 7 & $188(\mathrm{SD} \pm 5.29)$ & $364(\mathrm{SD} \pm 7.21)$ & $556(\mathrm{SD} \pm 9.17)$ \\
Sample 8 & $355(\mathrm{SD} \pm 10.00)$ & $768(\mathrm{SD} \pm 8.00)$ & $991(\mathrm{SD} \pm 9.54)$ \\
\hline
\end{tabular}


$6 " x 3.25 "$ which being quite heavy. The result indicated that operational convenience is playing a significant role in the recovery, but undoubtedly, gauss power is more important than the shape of the magnet and operational convenience.

\section{Least count (readability) of the balance}

The balance having $0.1 \mathrm{mg}$ least count (LC) gave accurate result compared to $1.0 \mathrm{mg} \mathrm{LC}$. The sample which recorded $650 \mathrm{mg} \mathrm{kg}-1$ of iron filings with the balance having $0.1 \mathrm{mg} \mathrm{LC}$, recorded only $500 \mathrm{mg} \mathrm{kg}^{-1}$ with the balance of $1.0 \mathrm{mg}$ LC (Table 3). Likewise, the sample with $1550 \mathrm{mg} \mathrm{kg}^{-1}$ recorded only $1200 \mathrm{mg} \mathrm{kg}^{-1}$ with the balance of $1.0 \mathrm{mg} \mathrm{LC}$. On the other hand, samples with 2850 and $3650 \mathrm{mg}$ $\mathrm{kg}^{-1}$ recorded 3000 and $3500 \mathrm{mg} \mathrm{kg}^{-1}$ respectively, with the balance of $1.0 \mathrm{mg} \mathrm{LC}$. The result thus indicated that lesser the LC, higher the accuracy of the result, as the sensitivity of the balance increases with decrease in LC.

Table 3. Impact of least count of balance on the accuracy of result on the estimation of iron filings

\begin{tabular}{lcc}
\hline Sample code & \multicolumn{2}{c}{$\begin{array}{c}\text { Least count of balance/ } \\
\text { Level of iron filings }\left(\mathbf{m g ~ k g}^{-1}\right)\end{array}$} \\
\cline { 2 - 3 } & $\mathbf{0 . 1} \mathbf{~ m g}$ & $\frac{\mathbf{1 . 0} \mathbf{~ m g}}{}$ \\
\hline Sample 1 & $650(\mathrm{SD} \pm 2)$ & $500(\mathrm{SD} \pm 0)$ \\
Sample 2 & $1550(\mathrm{SD} \pm 5)$ & $1200(\mathrm{SD} \pm 0)$ \\
Sample 3 & $2850(\mathrm{SD} \pm 5)$ & $3000(\mathrm{SD} \pm 0)$ \\
Sample 4 & $3650(\mathrm{SD} \pm 10)$ & $3500(\mathrm{SD} \pm 50)$ \\
\hline
\end{tabular}

\section{Effect of pre and post magnetic separation grinding}

Iron filing level estimated following DGHS method was exorbitantly high for all the samples compared to the methods wherein pre and post magnetic separation grinding were adopted. The value obtained with the BIS method was 50 per cent less than that of the value obtained with the DGHS method. The value obtained with the modified BIS procedure (UPASI method) was 80 per cent less than that obtained with BIS procedure (Table 4). The result thus revealed the importance of sample preparation as well as post magnetic separation grinding and refinement. The higher value obtained with the DGHS method was obviously due to the heterogeneity of the sample,

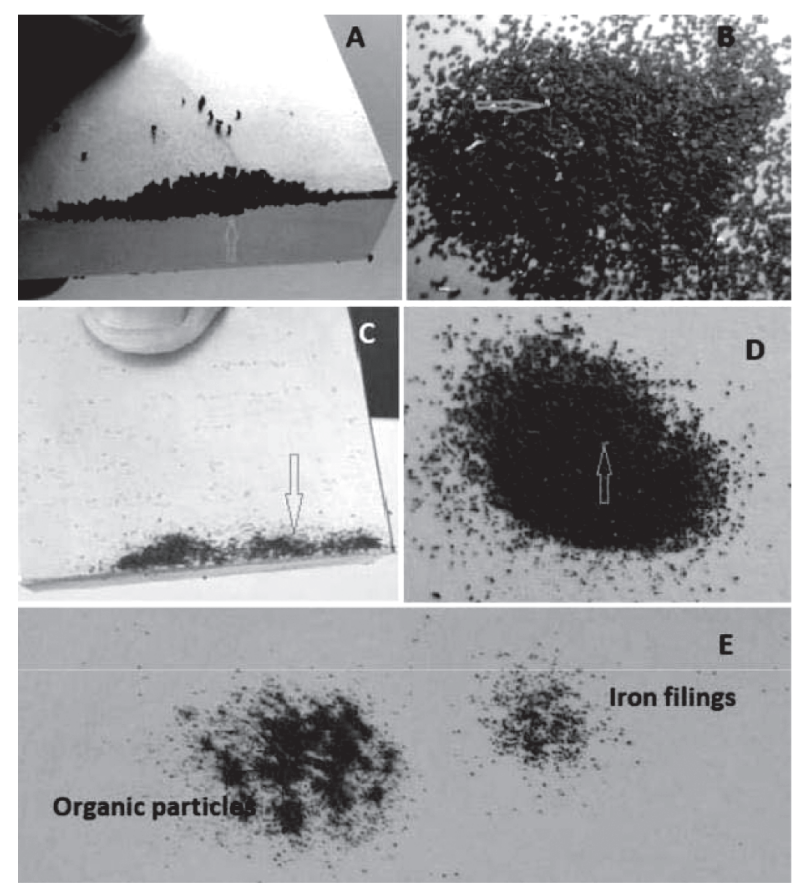

Fig. 1. Separation of Iron filings from made tea A, B: Sample without pre -magnetic separation grinding. C,D: Sample after grinding and sieving through $500 \mu$ sieve. A \& C: 'Iron filings' cling on the magnet. B \& D: Separated 'Iron filings' spread on a sheet of paper (iron filings not entrapped in leaf particles marked with arrow mark). E: 'iron filings' after post magnetic separation grinding and refinement (showing actual iron filings and separated organic particles)

coupled with the interference of organic particles (Fig. 1 A \& B). Sample preparation (grinding and sieving) brings down the heterogeneity of the analyte (Fig. $1 \mathrm{C} \& \mathrm{D}$ which in turn reduces the level of organic particles associated with iron filings. Post magnetic separation grinding and refinement will eliminate all organic particles and provide pure iron filings (Fig. 1 E). Any calculation based on the reading obtained along with the organic particle will not be an accurate representation of the iron filings content of the lot. Thus the study confirms the necessity of post magnetic separation grinding of 'iron filings' and its refinement to get the actual level of iron filings.

\section{Variation in the result on iron filings reported by commercial labs}

Level of iron filings reported by different commercial laboratories varied widely for the same 
Table 4. Impact of pre and post magnetic separation grinding of the sample on the estimation of iron filings

\begin{tabular}{|c|c|c|c|c|}
\hline \multirow{2}{*}{$\begin{array}{l}\text { Sl. } \\
\text { No. }\end{array}$} & \multirow[t]{2}{*}{ Blend No. } & \multicolumn{3}{|c|}{ Level of iron filings $\left(\mathrm{mg} \mathrm{kg}^{-1}\right) *$} \\
\hline & & Sample 1 & Sample 2 & Sample 3 \\
\hline 1. & $\begin{array}{l}\text { DGHS method (without sample preparation } \\
\text { and post magnetic separation grinding) }\end{array}$ & c212 \pm 165.92 & c2953 \pm 365.27 & ${ }^{c} 1986 \pm 33.95$ \\
\hline 2. & $\begin{array}{l}\text { BIS method (with sample preparation and without } \\
\text { post magnetic separation grinding) }\end{array}$ & b $1078 \pm 88.47$ & b1461 \pm 105.78 & b856 \pm 27.46 \\
\hline 3. & $\begin{array}{l}\text { UPASI Method (modified IS3633: 2003. with sample } \\
\text { preparation and post magnetic separation grinding) }\end{array}$ & a202 \pm 18.33 & a $256 \pm 19.28$ & ${ }^{\mathrm{a}} 114 \pm 7.00$ \\
\hline & $\mathrm{F}$ value & $\begin{array}{c}256.05524 \text { at } \\
\text { p value }<0.00001\end{array}$ & $\begin{array}{l}119.232 \text { at } \\
\text { p value }<0.00001\end{array}$ & $\begin{array}{c}4084.664 \text { at } \\
\text { p value }<0.00001\end{array}$ \\
\hline & Error $(\%)$ & 86.58 & 86.79 & 95.67 \\
\hline
\end{tabular}

*With magnet of 5000 Gauss power; Each value mean of Triplicate with \pm SD; The superscripted letters denote the variation among treatment according to DMRT

sample (Table 5). Out of the 15 test samples, only one sample failed $\left(>250 \mathrm{mg} \mathrm{kg}^{-1}\right)$ as per the report of Lab 1, while four samples failed by Lab 3. On the contrary, none of the samples failed as per the report of Labs 2, 4 and 5. It is to be noted that the result of Lab 3 was always on a higher side, while that of Lab 5 was too low. Variation in the result may be attributed to the difference in the gauss power of the magnet used by the labs and also the difference in their analytical procedure. Though labs 2, 3 and 4 used magnet of the same gauss power $(2000 \mathrm{G})$, lab 3 got significantly higher value

Table 5. Variation in the results on iron filings generated by commercial laboratories

\begin{tabular}{|c|c|c|c|c|c|c|c|c|c|}
\hline & & \multicolumn{4}{|c|}{ Level of iron filings $\left(\mathrm{mg} \mathrm{kg}^{-1}\right)$} & \multirow{2}{*}{\multicolumn{2}{|c|}{ LAB $5 * * *$}} & \multirow[t]{2}{*}{ SD } & \multirow[t]{2}{*}{ Error $(\%)$} \\
\hline & & LAB 1* & LAB $2 * *$ & LAB $3 * * \#$ & LAB $4 * *$ & & & & \\
\hline 1. & Sample 1 RD & 64 & 26 & 124 & 38 & 16 & & & \\
\hline 2. & Sample 2 RD & 88 & 24 & 112 & 42 & Absent & & & \\
\hline 3. & Sample 3 RD & 80 & 40 & 144 & 56 & 24 & & & \\
\hline 4. & Sample 4 RD & 70 & 36 & 120 & 42 & 12 & & & \\
\hline \multirow[t]{2}{*}{5.} & Sample 5 RD & 52 & 22 & 96 & 24 & Absent & & & \\
\hline & Average (RD) & 70.8 & 29.6 & 119.2 & 40.4 & 17.3 & 55.46 & 40.77 & 73.52 \\
\hline 6. & Sample 6 SRD & 75 & 48 & 112 & 44 & Absent & & & \\
\hline 7. & Sample 7 SRD & 92 & 44 & 165 & 38 & 24 & & & \\
\hline 8. & Sample 8 SRD & 75 & 25 & 106 & 32 & Absent & & & \\
\hline 9. & Sample 9 SRD & 60 & 26 & 102 & 28 & 12 & & & \\
\hline \multirow[t]{2}{*}{10.} & Sample 10 SRD & 82 & 46 & 118 & 42 & 20 & & & \\
\hline & Average (SRD) & 76.8 & 37.8 & 120.6 & 36.8 & 18.7 & 58.14 & 40.85 & 70.26 \\
\hline 11. & Sample 11 SFD & 117 & 56 & 277 & 85 & 32 & & & \\
\hline 12. & Sample 12 SFD & 112 & 64 & 204 & 92 & 40 & & & \\
\hline 13. & Sample 13 SFD & 122 & 56 & 256 & 103 & 46 & & & \\
\hline 14. & Sample 14 SFD & 152 & 88 & 266 & 116 & 72 & & & \\
\hline \multirow[t]{2}{*}{15.} & Sample 15 SFD & 314 & 108 & 565 & 150 & 80 & & & \\
\hline & Average (SFD) & 163.4 & 74.4 & 313.6 & 109.2 & 54 & 142.92 & 104.03 & 72.79 \\
\hline
\end{tabular}

*Magnet of 5000 Gauss power, **Magnet of 2000 Gauss power, *** Used horseshoe magnet (Gauss power not known), \#Not adopted pre-magnetic separation grinding 
because they did not adopt pre-magnetic separation grinding (sample preparation).

Extremely low value Iron filings in tea reported by lab 5 was obviously because of the type of magnet (horseshoe magnet) that they have used. On the contrary, fairly high values reported by Lab 1 was due to the higher Gauss power of their magnet $(5000 \mathrm{G})$ coupled with the fine tuning of the methodology (post magnetic separation grinding and refinement) to eliminate organic particle for getting pure iron filings.

Further, the result presented in Table 5 indicated that the mean value for iron filings reported by five commercial labs varied from 55.46 to 142.92 with SD value varied from 40.77 to 104.03 . The error of analysis for all the grades was approximately 70 per cent. The validity of a procedure having such an error is questionable, and it confirms the necessity of the refinement of the procedure by minimizing the possible error factors.

The result also revealed that the level of iron filings, in general, was higher in SFD grade followed by SRD and RD (Table 5). This trend further confirmed the result obtained from a large scale experiment wherein samples of various grades of CTC dust tea were collected from bulk packets of
20 different estates in south India (Fig. 2). Manigandan et al. (2016) observed a higher level of iron filings in leaf grades followed by dust and fannings in CTC teas. The present study though restricted to CTC dust grade alone, it is clear that the bolder grades (RD and SRD) had a lower level of iron filings compared to finer grade (SFD), i.e., the level of iron filings is in the order of SFD > $\mathrm{SRD}>\mathrm{RD}$ in dust grade teas. The trend was consistent (Fig. 2) and so it may be logically concluded that the trend in CTC tea should be in the order of Dust $>$ Fannings $>$ Leaf and not Leaf $>$ Dust $>$ Fannings as reported by Manigandan et al. (2016).

\section{Iron-fortified experiments}

\section{Level of iron filings $v s$ bulk density of tea}

The level of iron filings had little influence on the density of tea. The result showed that the density was unaffected even when the iron filings level was $1000 \mathrm{mg} \mathrm{kg}^{-1}$. On the other hand, only a slight decrease in free flow as well as compact density could be noticed with the sample wherein the iron filing level was as high as $3000 \mathrm{mg} \mathrm{kg}^{-1}$ (Table 6). From the result, it may be concluded that since the permissible level of iron filings as per FSSAI

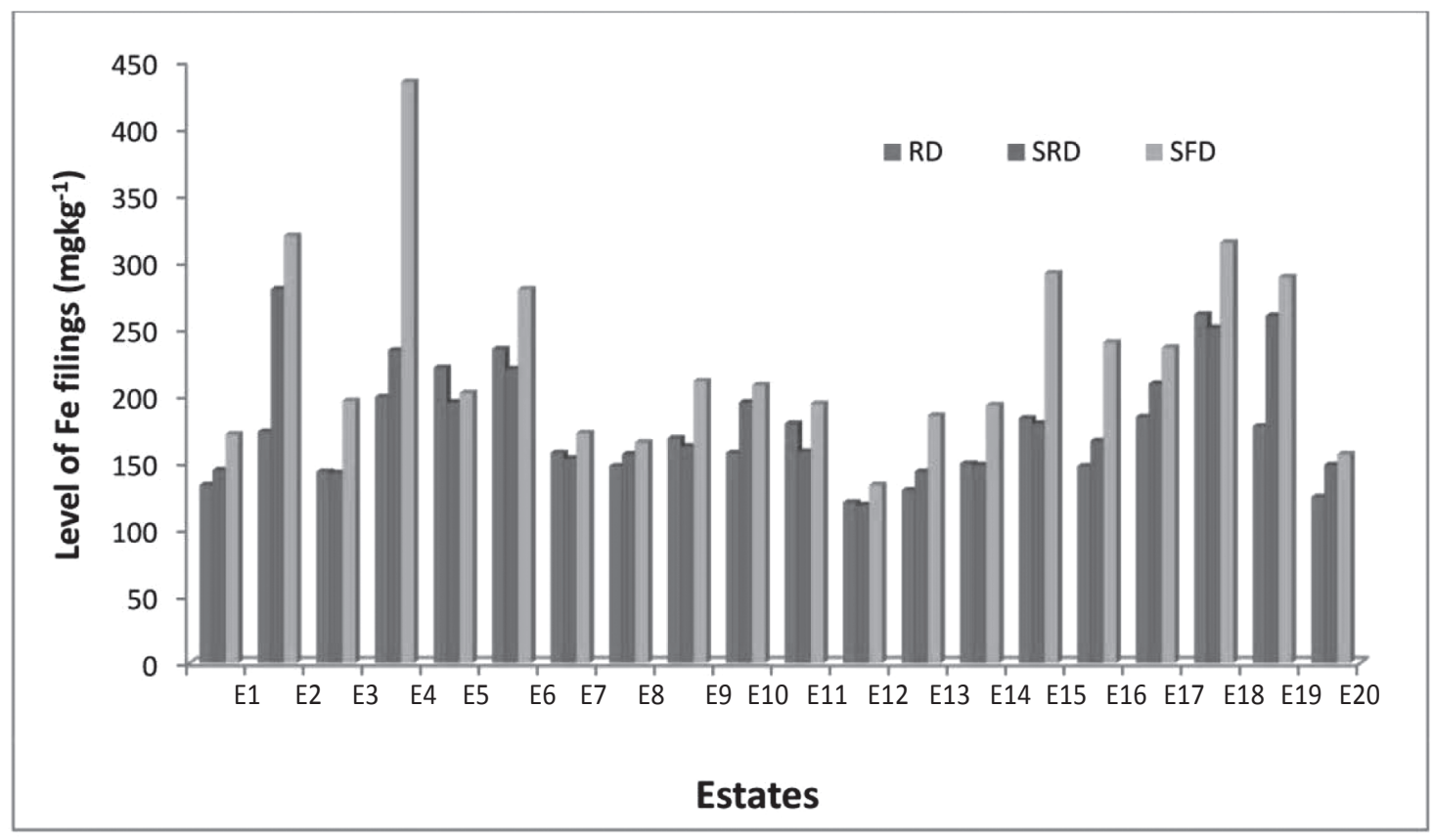

Fig. 2. Level of iron filings in different grades of CTC dust tea 
Table 6. Level of iron filings on density of tea

\begin{tabular}{llccc}
\hline & Samples & $\begin{array}{c}\text { Level of } \\
\text { iron filings } \\
\left(\mathbf{m g ~ k g}^{-1}\right)\end{array}$ & \multicolumn{2}{c}{$\begin{array}{c}\text { Density } \\
\left(\mathbf{c m}^{\mathbf{3}} \mathbf{1 0 0} \mathbf{~ g}^{-1}\right)\end{array}$} \\
\hline 1 & Mree flow Compact \\
2 & MT-L (Low) & 76 & 176 & 160 \\
3 & MT-H (High) & 232 & 176 & 160 \\
4 & MT-VH (Very high) & 1113 & 176 & 160 \\
5 & MT-EH (Extremely high) & 3072 & 174 & 158 \\
\hline
\end{tabular}

specification is $250 \mathrm{mg} \mathrm{kg}^{-1}$ and its level affects the density only in a very high level of $3000 \mathrm{mg} \mathrm{kg}^{-1}$ the scope for increasing the weight of tea by adulterating it with iron filings is only very little.

Bulk density is one of the quality attributes of tea because density is having a direct correlation with the particle size of tea dhool (tea powder). Generally, denser tea is better in quality compared to flake tea. However, in the present study, the density has no role in determining the quality because the decrease in density is the contribution of iron particles present in the sample and not because of a change in particle size of tea dhool.

\section{Level of iron filings vs quality attributes of tea}

\section{a. Effect on water extract and water-soluble ash}

As the level of iron filings increased, water extract (WE) and water-soluble ash (WSA) of made tea (MT) gradually decreased, while the colour value (CV) of liquor increased (Table 7). Though the level of WE and WSA were within FSSAI limit even in sample MT-EH where the iron filing level was $>3000 \mathrm{mg} \mathrm{kg}^{-1}$, gradual reduction in their values is an indication on the deterioration in quality of MT. Water extract and WSA are important parameters indicating the strength of liquor and have a direct correlation with cuppage of tea, i.e., higher the value better the quality. The result thus confirms that an increase in the level of iron filings can adversely affect the quality of made tea. This is further evident from the CV of tea liquor. Since CV is the representation of per cent transmission of light in a colorimeter, the correlation is negative i.e., lesser the value better the colour.

\section{b. Total iron}

The estimation of total iron (inherent iron + iron filings) in MT indicated that the level of total iron has not increased in line with the increase in the level of iron filings (Table 7). Level of total iron was higher than that of iron filings only in sample MT-L, while in all others it was less. The estimated iron filings in sample MT-M was 200 per cent more than that of MT-L, but the total iron was increased only by 45 per cent. When the iron filings level was increased by 600 per cent in MT- H, total iron was increased only by 60 per cent. Likewise, when iron filing level increased by 1300 per cent in MT-VH and 3900 per cent in MT-EH, increase in total iron was only 63 per cent and 80 per cent respectively. This variation may be attributed to the heterogeneity of the samples. i.e., though the sample is ground to powder and sieved, the iron particles need not be distributed homogenously in the sample. Further, the sample required for the analysis in ICPOES is too little $(500 \mathrm{mg})$, which increases the chances of

Table 7. Effect of the level of iron filings on tea quality parameters and total iron

\begin{tabular}{|c|c|c|c|c|c|c|c|c|}
\hline \multirow{2}{*}{$\begin{array}{l}\text { Sl. } \\
\text { No. }\end{array}$} & \multirow{2}{*}{ Sample } & \multirow{2}{*}{$\begin{array}{c}\text { Level of } \\
\text { iron filings } \\
\left(\mathrm{mg} \mathrm{kg}^{-1}\right)\end{array}$} & \multirow[b]{2}{*}{$\begin{array}{c}\text { Colour } \\
\text { value }\end{array}$} & \multirow[b]{2}{*}{$\begin{array}{c}\text { Water } \\
\text { extract } \\
(\%) \\
\text { (Not less than } \\
\text { 32\%)\% }\end{array}$} & \multirow[b]{2}{*}{$\begin{array}{c}\text { Water } \\
\text { soluble ash } \\
(\%) \\
(\text { Not less } \\
\text { than } 40 \%) \%\end{array}$} & \multicolumn{2}{|c|}{ Total iron } & \multirow{2}{*}{$\begin{array}{c}\text { Per cent } \\
\text { solubilization } \\
\text { of iron in to } \\
\text { tea liquor }\end{array}$} \\
\hline & & & & & & $\begin{array}{c}\text { Tea } \\
\text { powder } \\
\left(\mathrm{mg} \mathrm{kg}^{-1}\right)\end{array}$ & $\begin{array}{c}\text { Tea } \\
\text { liquor } \\
\left(\mathrm{mg} \mathrm{L}^{-1}\right)\end{array}$ & \\
\hline 1. & MT-L (Low) & 76 & 35 & 39.47 & 60.61 & 105.58 & 1.91 & 1.8090 \\
\hline 2. & MT-M (Medium) & 232 & 35 & 39.10 & 60.52 & 190.19 & 1.18 & 1.6204 \\
\hline 3. & MT-H (High) & 588 & 36 & 39.17 & 59.39 & 259.93 & 3.50 & 1.3465 \\
\hline 4. & MT-VH (Very high) & 1113 & 39 & 38.62 & 59.07 & 286.25 & 1.73 & 0.6043 \\
\hline 5. & MT-EH (Extremely high) & 3072 & 40 & 37.9 & 56.08 & 526.00 & 2.82 & 0.5361 \\
\hline
\end{tabular}

*As per FSSAI specification 
missing iron particles in the weighed sample due to its heterogeneous distribution.

There was no correlation between the total iron content in MT and in tea liquor (infusion/brew). Iron infused from MT into tea liquor during brewing was highest in sample MT-H followed by MT-EH and MT- L. However, it is interesting to note that the level of iron brought in to tea liquor was $<2$ per cent in all samples, irrespective of the level of total iron in MT (Table 7). Iron solubilized from made tea into the liquor was highest in MT-L (1.8\%) and gradually reduced in successive samples which were perfectly in line with the increase in level of iron filings. Accordingly, it was 1.62 per cent in MT-M and 1.35 per cent in MT-H brew. In the rest two samples, where the iron filings level was exorbitantly high, the level of total iron reduced drastically. In the case of sample MT-VH, it was 0.60 per cent, and for MT-EH it was 0.54 per cent. This drastic reduction could be due to the quantity of tea dhool present in the sample used for preparing the brew. i.e., as the quantity of iron particles increases the quantity of tea $d$ hool will be naturally reduced in the $2 \mathrm{~g}$ of the sample taken for the preparation of brew. Natesan and Ranganathan (1990) made critical studies on the total content of various mineral elements in made tea and infusion. They found that only a fraction of the element in the tea tissue is solubilized and infused into the liquor during brewing. The extent of solubility varies with elements; some are highly soluble $(\mathrm{K})$, some are readily soluble $(\mathrm{P}, \mathrm{Mg})$, certain others are moderately soluble $(\mathrm{Ca}, \mathrm{Al})$ and so on. Iron is in the category of 'less soluble elements' and they found that during brewing, $<10$ per cent of the total content of these elements infused in to the liquor.
This observation has practical utility in assessing the amount of minerals ingested through drinking tea. Natesan and Ranganathan (1990) reported that the less soluble elements are present in tea liquor in the range of $1-6 \mu \mathrm{g} \mathrm{g}^{-1}$ made tea.

Thus the present study indicated that iron solubilized into the liquor is very low $(<2 \%)$ and most likely it could be the contribution of inherent iron. Iron filings will not dissolve in hot water and so sediments and settle down in the bottom of the teapot.

Tea liquor is filtered through a strainer and decanted before drinking and so there is no chance of direct intake of iron filings into the body. Probably to a very small level, iron particles which are too small (colloidal) can be infused into the liquor. However, the result of total iron in tea liquor indicated that the chances for this are relatively low and even if there is, it will be negligible. It has already been reported that some of the elements present in tea liquor are good for human health (Gurses, 1987). Although the amount of $\mathrm{Cu}$ and $\mathrm{Fe}$ in tea liquor is low, it has been reported that tea may be effective in treating anaemia because of the haemopoietic and erythropoietic properties of its $\mathrm{Cu}$ and $\mathrm{Fe}$ content. So it may be concluded that iron filings in the tea will not cause any health hazard. Health benefit of tea has already been reported (McKay and Blumberg, 2002; Baby, 2004).

\section{c. Biochemical parameters}

Analysis of tea liquor for the biochemical parameters (cup quality) indicated that as the level of iron filings increases there was a decrease in theaflavins (TF), high polymerized substances (HPS), total liquor colour (TLC) and colour index (CI),

Table 8. Level of iron filings on tea liquor quality

\begin{tabular}{|c|c|c|c|c|c|c|c|}
\hline $\begin{array}{l}\text { Sl. } \\
\text { No. }\end{array}$ & Sample & $\begin{array}{c}\text { Theaflavin } \\
\text { (TF) }\end{array}$ & $\begin{array}{l}\text { Thearubigin } \\
\text { (TR) }\end{array}$ & $\begin{array}{c}\text { High } \\
\text { polymerized } \\
\text { substance } \\
\text { (HPS) } \\
\end{array}$ & $\begin{array}{l}\text { Total liquor } \\
\text { colour } \\
\text { (TLC) }\end{array}$ & $\begin{array}{l}\text { Colour } \\
\text { index } \\
(\mathrm{CI})\end{array}$ & TR: TF \\
\hline 1. & MT-L (Low) & 0.76 & 8.16 & 10.20 & 3.56 & 4.14 & 10.73 \\
\hline 2. & MT-M (Medium) & 0.74 & 8.76 & 10.18 & 3.50 & 3.92 & 11.84 \\
\hline 3. & MT-H (High) & 0.73 & 9.60 & 10.04 & 3.48 & 3.72 & 13.15 \\
\hline 4. & MT-VH (Very high) & 0.72 & 9.62 & 10.04 & 3.42 & 3.66 & 13.36 \\
\hline 5. & MT-EH (Extremely high) & 0.72 & 9.84 & 10.14 & 3.34 & 3.6 & 13.66 \\
\hline
\end{tabular}

Colour Index $=$ TF x 100/ TR + HPS 
but an increase in thearubigins (TR) content (Table 8). The TF and HPS were highest in MT-L, so the case of TLC and colour index. Among the biochemical parameters, TF is having a direct correlation with the quality and price realization of tea. Ranganath and Raju (1991) reported that it is not the maximum value of TF, but a proper balancing of TF and TR that decides the quality of tea. They also opined that a TR/TF ratio of $1: 10$ to $1: 12$ is ideal. In the present study, it was found that TR/TF ratio of sample MT-L was 10.73 , indicating that the liquor parameters are best in this sample compared to others. The higher TR/TF ratio of the rest of the sample is again an indication of the deterioration of the quality of MT with respect to the increase in the level of iron filings. Theaflavins and thearubigins are formed during the fermentation process by the degradation of catechins. Theaflavins are responsible for brightness and briskness of tea liquor, while thearubigins contribute to its colour and depth (body and strength).
In organoleptic evaluation (sensory evaluation/ tea tasting) tasters rated MT- L as the best followed by MT- M and MT- EH as the least. The organoleptic evaluation of the tea samples having various levels of iron filings perfectly matches with the results obtained with chemical and biochemical analyses. Taster's evaluation further substantiates that increase in level of iron filings deteriorates the quality of tea (Table 9).

There is an apprehension that tea is being adulterated with iron filings including rusted iron powder to increase weight and to impart improved colour to the tea liquor. The present study proved beyond doubt that weight leverage could be achieved only with a very high level of iron filings (Table 6) but the liquor characters deteriorated with a much lower level of iron filings itself (Table 7, 8). It is also noted that the liquor became dull, thick and loses flavour and became harsh and bitter when the iron filings level was high. When the rusted iron powder was added to made tea, the tea liquor

Table 9. Level of iron filings on organoleptic evaluation of tea

\begin{tabular}{|c|c|c|c|c|}
\hline $\begin{array}{l}\text { Sl. } \\
\text { No. }\end{array}$ & Sample & Appearance & Liquor & Infused leaf \\
\hline 1. & MT-L (Low) & $\begin{array}{l}\text { Very slight brown, apparently clean, } \\
\text { mixed appearance, slightly flaky }\end{array}$ & $\begin{array}{l}\text { Much coloury, very slight cloudy. } \\
\text { Slightly thin, more sour, little flavoury, } \\
\text { no harsh, slight bitter, little strong }\end{array}$ & $\begin{array}{l}\text { More coppery, } \\
\text { medium sized } \\
\text { infusion }\end{array}$ \\
\hline 2. & $\begin{array}{l}\text { MT-M } \\
\text { (Medium) }\end{array}$ & $\begin{array}{l}\text { Apparently black, clean \& } \\
\text { medium size }\end{array}$ & $\begin{array}{l}\text { More plus coloury, bright. } \\
\text { Slightly thicker than MT-L, less sour, } \\
\text { little harsh, very slight bitter, } \\
\text { very little flavour }\end{array}$ & $\begin{array}{l}\text { Medium coppery } \\
\text { and smaller }\end{array}$ \\
\hline 3. & $\begin{array}{l}\text { MT-H } \\
\text { (High) }\end{array}$ & $\begin{array}{l}\text { Very slight brown and smaller, } \\
\text { apparently clean }\end{array}$ & $\begin{array}{l}\text { Much coloury, slightly dull. Little thick, } \\
\text { very less flavour, little harsh and slight } \\
\text { bitter. (lower than MT-M and MT-L) }\end{array}$ & $\begin{array}{l}\text { Slightly dull and } \\
\text { slightly bolder than } \\
\text { FBL }\end{array}$ \\
\hline 4. & $\begin{array}{l}\text { MT-VH } \\
\text { (Very high) }\end{array}$ & $\begin{array}{l}\text { Very slight brown, } \\
\text { clean and powdery }\end{array}$ & $\begin{array}{l}\text { Much coloury, little dull. Little thick, } \\
\text { no flavour, very less sour, less harsh, } \\
\text { very slight bitter. } \\
\text { (Totally lower than previous } \\
\text { three samples) }\end{array}$ & $\begin{array}{l}\text { Coppery and } \\
\text { slightly powdery } \\
\text { infusion }\end{array}$ \\
\hline 5. & $\begin{array}{l}\text { MT-EH } \\
\text { (Extremely } \\
\text { high) }\end{array}$ & $\begin{array}{l}\text { Apparently black, clean } \\
\text { and slightly powdery }\end{array}$ & $\begin{array}{l}\text { Much coloury, slightly dull, slight thick, } \\
\text { no flavour, no bitter, more sour } \\
\text { (lower than all other sample) }\end{array}$ & $\begin{array}{l}\text { Medium coppery } \\
\text { and slightly bolder } \\
\text { infusion }\end{array}$ \\
\hline
\end{tabular}


Iron filings in tea

Table 10. Impact of rusted iron powder on cup quality

\begin{tabular}{lllll}
\hline $\begin{array}{l}\text { Sl. } \\
\text { No. }\end{array}$ & Blend code & $\begin{array}{l}\text { Colour } \\
\text { value }\end{array}$ & \multicolumn{2}{c}{ Liquor quality } \\
\cline { 3 - 4 } & & Without milk & With milk \\
\hline $\begin{array}{l}\text { 1. } \\
\text { Sample A } \\
\text { (Control) }\end{array}$ & 35 & $\begin{array}{l}\text { liquor was little dense, barely seen the } \\
\text { bottom of the cup, little harsh }\end{array}$ & $\begin{array}{l}\text { More coloury plus, slight harsh, } \\
\text { slight bitter but pleasant }\end{array}$ \\
2. & $\begin{array}{l}\text { Sample B } \\
\text { (Adulterated) }\end{array}$ & 38 & liquor was more dark, more harsh & Coloury plus, little cloudy, harsh \\
\hline
\end{tabular}

became dark and harsh. This was reflected in the colour value as well. Further, the liquor became cloudy and harsh, with the addition of milk (Table 10). Thus the study confirms that as the level of iron filings increases the quality of tea deteriorates, and so there is very little scope for such an adulteration.

Iron is not enlisted in poisonous metals (metal contaminants) under clause 2.1.1 of Food Safety Standards Regulation (2015) of FSSAI act. Iron is an essential micronutrient which plays a vital role in many physiological processes. The present study reveals that the iron present in tea liquor is the one infused from the inherent iron. Inherent iron ingested through normal dietary sources does not cause any health hazard. Further, tea is not directly consumed, only the tea liquor is being drunk, and so there is no possibility of iron filings entering into the body through tea liquor. Thus the present investigation confirms that the presence of iron filings in tea need not be considered as a threat to human health. It is pertinent to mention here that FSSAI has revised the limits for iron filing from $150 \mathrm{mg} \mathrm{kg}^{-1}$ to $250 \mathrm{mg} \mathrm{kg}^{-1}$ based on the studies conducted by the National Institute of Nutrition, Hyderabad (FSSAI, 2016; FSSAI, 2017; Baby, 2017).

\section{Conclusion}

The present investigation revealed the limitations of the procedure adopted for the estimation of iron filings in tea. There are several factors which can affect the accuracy of the result. The standard (IS 3633) specifies to use a powerful magnet for the operation. The present study revealed that the gauss power of the magnet and post magnetic separation grinding are more important than that of handiness in operation. Shape of the magnet and the least count of balance also have important roles in determining the accuracy of the result. So the standard should have specifications on shape, size and gauss power of the magnet to get an accurate and reproducible result. It is also evident that the increase in the level of iron filings deteriorates the quality of MT as well as tea liquor. Water extract and Watersoluble ash content gradually decreased while colour value increased with increase in the level of iron filings. The liquor quality parameters like theaflavin, HPS, TLC and colour index decreased while thearubigins increased with increase in the level of iron filings. Further TR/ TF ratio, a key factor on tea liquor quality, was maintained at the ideal level $(1: 10$ to $1: 12)$ where iron filings level was low. Further, analysis of total iron indicated that its level did not increase in line with the increase in the level of iron filings. Organoleptic evaluation of tea by professional tea tasters confirms the deterioration of the quality of MT due to the presence of iron filings beyond a certain limit and corroborates the biochemical observations. The result also indicated that the iron solubilized into the liquor was less than 2 per cent and is the contribution of inherent iron and not that of iron filings. This observation confirms that there is no possibility of direct ingestion of iron filings and hence does not pose a threat to human health. Infact, inherent iron is beneficial as it is nutritional in nature. The density of tea was affected only when the iron filings level was extremely high and so achieving weight leverage by adding iron as an adulterant has only very little scope.

\section{Acknowledgement}

I am thankful to Dr. N. Muraleedharan, former Director of UPASI TRF- TRI, Valparai and Tea 
Research Association, Tocklai, Dr. R. S. Senthilkumar, former Tea Technologist, UPASI TRI and Mr. G. Venkateswaran, Senior Advisory officer UPASI TRF, Coonoor for useful discussions and Mr. R. Kumaraguru Advisory Officer, UPASI TRF, Wayand for being a resource person. Thanks are also due to Mr. Murugesan former Tea Technologist UPASI TRI and Dr. (Prof) H.D.Subashini, my former colleague in CAS in Botany, University of Madras for statistical analysis, Mr. Hamlin and Mr. Padmanandan, AVT-CPD for certain analytical assistance and Mr. Aravind Baby, Indian Institute of Science, Bangalore for technical discussions.

\section{References}

Anonymous. 1997. Towards total quality management: Iron filings in tea. Tea Board of India. 21p.

Baby, U.I. 2004. Tea: A healthy drink. Science India 7(1): 42-43.

Baby, U.I. and Murugesan, S. 2009. Iron filings in tea. Planters' Chronicle 105 (6): 5-10.

Baby, U.I. 2016. Iron filings in tea. Factors influencing accuracy of test result. Contemporary Tea Time XXXV (1\&2): 44-45.

Baby, U.I. 2017. New norms on iron filings: Food safety standards of tea vis-à-vis revised regulation. Contemporary Tea Time XXXVI (1): 43.

BIS (Bureau of Indian Standards) 1994.Tea - Preparation of ground sample of known dry matter content (Reaffirmed 1999), IS 13852 (ISO1572:1980), 2p.

BIS (Bureau of Indian Standards) 1999. Tea - Determination of water extract, IS 13862 (ISO 9768:1994) 3p.

BIS (Bureau of Indian Standards) 2003. Black tea specifications (second revision), IS 3633, 7p.

DGHS (Directorate General of Health Services) 2005. Manual of Analysis of Foods, Beverages (Coffee, Tea, Cocoa, Chicory), Sugar and Sugar Products. (Lab manual 4), Ministry of Health and Family Welfare, Govt. of India, New Delhi. 146p.

Egyptian Standards 2005. Tea and methods of analysis and testing. Part 1. Tea (ES: 559 -1), 11p.

FSSAI (Food Safety Standards Authority of India) 2015.The Food Safety Standards Act 2006 (Act No. 34 of 2006 dated 23.08.2006). $6^{\text {th }}$ Edn, Aug 2015. Commercial Law Publishers (India) Pvt. Ltd., New Delhi.

FSSAI (Food Safety Standards Authority of India) 2016. Food Safety and Standards (Food product standards and food additives) Amendment regulations, 2016 relating to limit of iron filings in Tea. F.No. P.15025/6/2004-PFS/FSSAI (Pt II), dated $1^{\text {st }}$ November 2016.

FSSAI (Food Safety Standards Authority of India) 2017. https:/ /foodsafetyhelpline.com/fssai-finalises-standards-limitiron-filings-tea/

GSO. 1998. Standard organization for GCC (GSO): GSO 978/ 1998 (ICS:67.140). 3p.

Gurses, O.L. 1987. The chemical composition of Turkish teas from the stand point of human health. In: Proceedings of International Tea Symposium, Rize, Ankara, Turkey. pp. 132-140.

ISIRI (Institute of Standards and Industrial Research Iran) 2012. Iranian National Standard No. 9266, food stuffsmeasuring $\mathrm{Pb}, \mathrm{Cu}, \mathrm{Fe}$ and $\mathrm{Zn}$ content- atomic absorption photometric method.

Manigandan, N., Surendar, P. and Suraj, R. 2016. Survey on the presence of iron filings in black tea (CTC and Orthodox) and green tea in south India. International Journal of Applied and Pure Science and Agriculture (IJAPSA) 02 (05): 165-168.

McKay, D.L. and Blumberg, J.B. 2002. The role of tea in human health: An update. Journal of American College of Nutrition 21(1): 1-13.

Natesan, S. and Ranganathan, V. 1990. Content of various elements in different parts of the tea plant and in infusions of black tea from southern India. Journal of Science for the Food and Agriculture 51: 125-139.

Ranganath, S.R. and Raju, K. 1991. Biochemical evaluation of Nilgiri teas. UPASI Tea Scientific Department Bulletin 44: 88-96.

Sri Lanka Tea Board. 2008. Sri Lanka Tea Board Standards for Sri Lanka origin tea. Law No 14 of 1975. 4p.

Takeo, T. and Oosawa, K. 1976. Photometric analysis and statistical evaluation of black tea infusion. Bullettin of National Research Institute of Tea (Japan) 12: 125-181.

Thanaraj, S.N. and Ramaswamy, S. 1977. Determination of iron particle content of black tea. Journal of Food Science and Technology 14 (6): 265-267. 